\title{
Pengaruh (Keselamatan dan Kesehatan Kerja) dan Stres Kerja Terhadap Kinerja Karyawan (Studi kasus pada PT. Ridar Essindo di Tangerang)
}

\author{
Lucia Maduningtias ${ }^{1}$, Oki Iqbal Khoir ${ }^{2}$ Tarwijo $^{3}$ \\ 1,2,3 Universitas Pamulang, Banten, Indonesia \\ E-mail:dosen01783@unpam.ac.id, dosen01801@unpam.ac.id, dosen01476@unpam.ac.id
}

\begin{tabular}{l}
\hline Article Info \\
\hline Article History \\
Received: 2021-05-12 \\
Revised: 2021-08-15 \\
Published: 2021-08-24
\end{tabular}

Keywords:

Safety;

Health;

Work;

Job Stress;

Performance.

\begin{abstract}
This research was conducted with the aim of knowing Occupational Safety and Health, Work Stress on Employee Performance. using descriptive quantitative analysis methods with survey approaches, questionnaires, and interviews. The population in this study were all 50 Ridar Essindo employees using saturated samples. The analysis technique used the validity test, reliability test, normality test, multicollinearity test, heteroscedasticity test, multiple linear regression analysis, coefficient of determination and correlation, $\mathrm{f}$ test, and $\mathrm{t}$ test.Based on the results of the calculation of multiple regression analysis obtained $\mathrm{Y}=21.096+0.645 \mathrm{X} 1+0.099 \mathrm{X} 2+6.205$. count is greater than $\mathrm{t}$-table of $4.358<1.677$ and the value of si gnification is smaller by $0.000<0.05$. Meanwhile, X2 has an effect but not significant on employee performance, seen from the $t$-count value is greater than the $t$-table of $0.793>1.677$ and the significance value is greater than $0.464>0.05$. Then through the test the coefficient of determination shows $\mathrm{R}$ of 0.533 which means there is a positive and strong relationship between occupational safety and health, work stress on employee performance. The coefficient of determination is 0.276 . This shows that $27.6 \%$, while $72.4 \%$ is influenced by other factors such as employee placement, job training, work environment and others. Based on the hypothesis testing that has been done using the $\mathrm{f}$ test, it is found that fcount = 27.396 and after being consulted with the ftable at a significant level of $5 \%$ and $n=(-3)$ shows ftable $=3.20$ which means that there is a positive influence between health and work safety, work stress on employee performance because fcount (27.396)> (3.20).
\end{abstract}

\begin{tabular}{l}
\hline Artikel Info \\
\hline Sejarah Artikel \\
Diterima: 2021-05-12 \\
Direvisi: 2021-08-15 \\
Dipublikasi: 2021-08-24
\end{tabular}

\section{Abstrak}

Penelitian bertujuan untuk mengetahui Keselamatan dan Kesehatan Kerja, Stres Kerja Terhadap Kinerja Karyawan. Penelitian ini menggunakan metode deskritif kuantitatif analisis dengan pendekatan survey, kuesioner, dan wawancara. Populasi dalam penelitian ini adalah seluruh karyawan Ridar Essindo yang berjumlah 50 orang dengan menggunakan sampel jenuh. Teknik analisis menggunakan uji validitas, uji reliabilitas, uji normalitas, uji multikolinieritas, uji heteroskedastisitas, analisis regresi linear berganda, koefisien determinasi dan korelasi, uji f, dan uji t. Berdasarkan hasil perhitungan analisis regresi berganda diperoleh $Y=21.096+0.645 \mathrm{X}_{1}+0.099 \mathrm{X}_{2}+$ 6.205. Hasil uji t menunjukkan bahwa variabel $X_{1}$ berpengaruh signifikan dilihat dari nilai t-hitung lebih besar dari t-tabel sebesar $4.358<1,677$ dan nilai signifikasi lebih kecil sebesar $0,000<0,05$. Sedangkan $X_{2}$ berpengaruh namun tidak signifikan terhadap kinerja karyawan dilihat dari nilai t-hitung lebih besar dari t-tabel sebesar 0,793 > 1,677 dan nilai signifikasi lebih besar sebesar 0,464 >0,05. Kemudian melalui uji koefisien determinasi menunjukkan $\mathrm{R}$ sebesar 0,533 yang berarti terdapat hubungan yang positif dan kuat antara keselamatan dan kesehatan kerja, stress kerja terhadap kinerja karyawan. Koefisien determinasinya sebesar 0,276. Hal ini menunjukkan sebesar $27,6 \%$, sedangkan $72,4 \%$ dipengaruhi oleh faktor lain seperti penempatan karyawan, pelatihan kerja, lingkungan kerja dan lain-lain. Berdasarkan pengujian hipotesis yang telah dilakukan dengan menggunakan uji $\mathrm{f}$ diperoleh bahwa $\mathrm{f}_{\text {hitung }}=$ 27,396 dan setelah dikonsultasikan dengan $\mathrm{f}_{\text {tabel }}$ pada taraf signifikan $5 \%$ dan $\mathrm{n}=(-3)$ menunjukkan $\mathrm{f}_{\text {tabel }}=3,20$ yang artinya terdapat pengaruh yang positif antara kesehatan dan keselamatan kerja, stres kerja terhadap kinerja karyawan karena $f_{\text {hitung }}$ $(27,396)>(3,20)$.

\section{PENDAHULUAN}

Manajemen dapat diartikan bekerja dengan orang-orang untuk mencapai tujuan organisasi dengan pelaksanaan fungsi-fungsi perencanaan, pengorganisasian, penyusunan personalia atau kepegawaian, pengarah dan 
kepemimpinan, dan pengawasan (Andri Feriyanto 2014:4). Jadi manajemen pada dasarnya adalah upaya mengatur segala sesuatu (sumber daya) untuk mencapai tujuan organisasi. Fungsi dari manajemen antara lain perencanaan, pengorganisasian penggerkan dan pengawasan.

PT. Ridar Essindo adalah perusahaan yang bergerak di bidang manufaktur dalam pembuatan berbagai jenis mesin baja yang terkait dengan semua jenis bidang teknik saat ini, metode penjahit per desain dan sesuai dengan spesifikasi gambar dan permintaan pelanggan, masalah Keselamatan dan Kesehatan Kerja pada perusahaan PT. Ridar Essindo memiliki resiko keselamatan dan resiko kesehatan dalam bidang kepegawaian. Keselamatan kerja menunjukkan kondisi yang aman selamat dari penderitaan, kerusakan atau kerugian ditempat kerja resiko keselamatan merupakan aspek-aspek dari lingkungan kerja yang dapat menyebabkan kebakaran, ketakutan aliran listrik, terpotong, luka memar, keseleo, patah tulang, kerugian alat tubuh penglihatan dan pendengaran semua itu sering dihubungkan dengan perlengkapan perusahaan atau lingkungan fisik yang mencakup tugas-tugas yang ada diperusahaan.

Permasalahan yang dihadapi dalam perusahaan ini yaitu kurang adanya ketaatan peraturan menggunakan prosedur APD (Alat Pelindung Diri) yang digunakan oleh seluruh karyawan sehingga menimbulkan banyaknya kecelakaan yang di alami karyawan, Perusahaan saat ini memiliki karyawan sebanyak 50 orang sehingga dapat dilihat bahwa terdapat masalah tentang Keselamatan dan Kesehatan Kerja (K3), K3 mengalami perubahan yang cukup signifikan, tabel berikut adalah rekap hasil dari Keselamatan dan Keseharan Kerja (K3) pada karyawan PT. Ridar Essindo

Tabel 1. Data Kecelakaan kerja PT. Ridar Essindo Indonesia Tahun 2018

\begin{tabular}{cccc} 
Bulan & Ringan & Sedang & Parah \\
\hline Januari & 2 & 0 & 1 \\
\hline Februari & 1 & 0 & 0 \\
\hline Maret & 4 & 0 & 0 \\
\hline April & 0 & 0 & 0 \\
\hline
\end{tabular}

Sumber : Data Internal PT. Ridar Essindo Tahun 2018

Tabel diatas menunjukan bahwa tingkat kecelakaan kerja ringan seperti luka terkena benda tajam terbanyak di bulan Maret sebanyak 4 kali, tingkat kecelakaan sedang tidak ada, dan tingkat kecelakaan parah di bulan Januari sebanyak 1 kali, seperti kehilangan anggota tubuh. Kejadian beberapa hal di atas diakibatkan kurangnya memperhatikan keamanan pada diri sendiri seperti tidak memakai APD (Alat Pelindung Diri) dan kurangnya mengikuti aturan yang telah ditentukan oleh perusahaan. Setelah terjadinya kecelakaan kerja, kemudian pada bulan April 2018 Program K3 yaitu program Keselamatan dan Kesehatan Karyawan lebih diperhatikan dan ditingkatkan lagi keamanannya sehingga meminimalisir terjadinya kecelakaan kerja dan adanya pengaruh ketelitian dalam bekerja.

Salah satu faktor yang mempengaruhi kinerja karyawan adalah keselamatan dan kesehatan kerja (K3) terhadap karyawan yang nantinya akan mempengaruhi pikiran, perasaan, sikap, dan perilaku organisasinya demi tercapainnya kinerja yang optimal. Program keselamatan dan kesehatan kerja saat ini sedang banyak di bicarakan oleh berbagai media elektronik dan artikel koran. Berbagai perusahaan menerapkan keselamatan dan kesehatan kerja guna untuk mendukung proses peningkatan kinerja karyawan. Tujuan utama keselamatan dan kesehatan kerja (K3) adalah agar karyawan atau pegawai di sebuah instansi mendapat kesehatan yang seoptimal mungkin sehingga mencapai produktivitas kerja yang setinggitingginya (Notoatmodjo, 2015).

Selain itu, beberapa peneliti sebelumnya menyatakan faktor-faktor yang mempengaruhi kinerja karyawan selain Keselamatan dan Kesehatan Kerja (K3) adalah stress kerja, berdasarkan penelitian terdahulu menemukan bahwa stres kerja mempengaruhi kinerja karyawan (Anggit Astianto dan Heru Suprihhadi 2014; Ashfaq Ahmed 2013; Riandy 2016; Meral Elcic 2016). Sementara, Keselamatan dan Kesehatan Kerja (K3) mempengaruhi kinerja karyawan (Steffany Elizabeth Leonora Lalu 2016; Agustin Pratiwi 2013; Mersya Anjani, Hamidah Nayati Utami, Arik Prasetya 2014), Dari observasi yang penulis lakukan pada PT Ridar Essindo, penulis melakukan pra-survey kepada 30 orang karyawan dan terdapat beberapa masalah yang karyawan alami dalam tahun 2020. penjabarannya pada tabel berikut: 
Tabel 2. Data Karyawan Keluar Kerja Pada PT. Ridar Essindo Tangerang

Bulan Jabatan $\begin{gathered}\text { Jumlah } \\ \text { karyawan } \\ \text { yang } \\ \text { keluar }\end{gathered}$ Ket

\begin{tabular}{llcc}
\hline Januari 2018 & Crew & 3 & $\begin{array}{c}\text { Pindah } \\
\text { kerja }\end{array}$ \\
\hline Maret 2018 & Crew & 1 & $\begin{array}{c}\text { Pindah } \\
\text { kerja }\end{array}$ \\
\hline April 2018 & Star crew & 2 & $\begin{array}{c}\text { Pindah } \\
\text { kerja }\end{array}$ \\
\hline Juli 2018 & Star crew & 1 & $\begin{array}{c}\text { Pindah } \\
\text { kerja }\end{array}$ \\
\hline $\begin{array}{l}\text { September } \\
\text { 2018 }\end{array}$ & Part Time & 3 & $\begin{array}{c}\text { Pindah } \\
\text { kerja }\end{array}$ \\
\hline Desember 2018 & Crew & 2 & $\begin{array}{c}\text { Pindah } \\
\text { kerja }\end{array}$ \\
\hline & Total & 12 & \\
\hline
\end{tabular}

Sumber: PT. Ridar Essindo Tangerang 2018

terkait data karyawan yang keluar dari perusahaan PT. Ridar Essindo, dari bulan Januari 2018 sampai dengan Desember 2018, tiap bulannya pasti ada saja karyawan yang keluar kerja, hal ini menunjukan bahwasannya dengan menurunya jumlah karyawan dapat menimbulkan beban kerja yang berlebih kepada karyawan yang masih bertahan. Dengan adanya beban kerja yang berlebihan menyebabkan tekanan dalam menyelesaikan pekerjaan. beban kerja juga dirasakan oleh karyawan karena pekerjaanya tidak fokus pada satu pekerjaan saja, satu orang karyawan bisa mengerjakan beberapa pekerjaan apabila salah satu karyawan tidak masuk kerja, suasana lingkungan counter yang kurang dingin sehingga karyawan kurang fokus dalam bekerja. Jadi kondisi tersebut sangat berpengaruh terhadap kinerja karyawan seta kondisi mental dan fisik karyawan yang dapat menyebabkan stres kerja. Dalam pengawasan pimpinan juga terlalu mendikte dan sulit sekali buat karyawan untuk bisa memberikan saran dan masukan situasi yang ada di dalam proses bekerja, sehingga inilah yang meyebabkan tingat emosi karyawan sering meninggi, hal sepele aja bisa menjadi masalah yang besar.

Tabel 3. Tabel Penilaian Kinerja Karyawan PT. Ridar Essindo

\begin{tabular}{lccc}
\hline \multirow{2}{*}{ Aspek Penilaian } & Target & \multicolumn{2}{c}{ Nilai Yang Dicapai } \\
\cline { 3 - 4 } & & $\begin{array}{c}\text { Hasil } \\
\text { Yang } \\
\text { Dicapai }\end{array}$ & Persentase \\
\hline Menjalankan SOP & 30 & 20 & $67 \%$ \\
\hline Memberikan Ide & 15 & 8 & $53 \%$ \\
\hline Menyelesaikan & 20 & 12 & $60 \%$ \\
\hline
\end{tabular}

\begin{tabular}{|c|c|c|c|}
\hline Tugas Tepat Waktu & & & \\
\hline $\begin{array}{ll}\text { Mencapai } & \text { Target } \\
\text { Perusahaan } & \end{array}$ & 20 & 12 & $60 \%$ \\
\hline $\begin{array}{l}\text { Menjalankan 3cs } \\
\text { (Communication, } \\
\text { Coordination, } \\
\text { Cooperation }\end{array}$ & 15 & 8 & $53 \%$ \\
\hline Total & 100 & 60 & $60 \%$ \\
\hline
\end{tabular}

Kriteria Penilaian :

$\begin{array}{ll}\text { Sangat Baik } & : 90> \\ \text { Baik } & : 75 \text { s.d } 89 \\ \text { Kurang Baik } & : 60 \text { s.d 74 } \\ \text { Sangat Tidak Baik } & : 45 \text { s.d } 59\end{array}$

Berdasarkan data pada tabel diatas dapat dilihat bahwa pada tahun 2018 pencapaian peniliaian kinerja karyawan sebesar 60 atau hanya mencapai $60 \%$ dari target yang ditentukan dan masuk dalam kriteria kurang baik. Dari data tersebut dapat disimpulkan bahwa setiap tahun kinerja karyawan mengalami penurunan, hal itu dapat disebabkan oleh kurang maksimal dan kurang bergairahnya karyawan dalam melakukan pekerjaannya. Perlu adanya evaluasi dari perusahaan agar tujuan perusahaan dapat dicapai, Berdasarkan uraian di atas, menjelaskan bahwa K3 (Keselamatan dan Kesehatan Kerja) dan Stres Kerja dengan kinerja karyawan, maka peneliti tertarik melakukan penelitian dengan judul "Pengaruh K3 Dan Stres Kerja Terhadap Kinerja Karyawan Pada PT. Ridar Essindo, Tangerang".

\section{METODE PENELITIAN}

Desain penelitian yang digunakan dalam penelitian kausal, penelitian kausal adalah hubungan yang bersifat sebab akibat dimana variabel independen mempengaruhi variabel dependen (Sugiono, 2016), dalam penelitian ini, peneliti tertarik untuk menguji hipotesis tentang pengaruh keselamatan dan kesehatan kerja (K3), stres kerja terhadap kinerja karyawan pada PT Ridar Essindo, Proses penelitian ini diawali dengan mengidentifikasikan permasalahan ditempat yang akan digunakan sebagai lokasi penelitian, perumusan masalah, pengumpulan dasardasar teori yang memperkuat landasan dalam variabel dan penentuan teknik pengujian statistik yang digunakan. Proses ini membutuhkan waktu penelitian mulai dari awal Januari hingga data terpenuhi, Penelitian ini dilaksanakan di PT Ridar Essindo yang beralamat di Jln. Raya Serang, Cikupa 
Tangerang, dengan Sampel yang ditetapkan dalam penelitian ini adalah semua karyawan di PT Ridar Essindo yang berjumlah sebanyak 50 orang.

\section{HASIL DAN PEMBAHASAN}

a) Gambaran Umum Objek Penelitian

PT. Ridar Essindo sangat senang memperkenalkan diri sebagai perusahaan yang bergerak dalam pembuatan berbagai jenis mesin baja yang terkait dengan semua jenis bidang teknik saat ini. Didirikan pada tahun 1999, kami telah mengalami pertumbuhan yang stabil selama 10 tahun terakhir, dan telah mengumpulkan banyak pengalaman di bidang ini berkat para pekerja terampil kami yang berpengalaman yang dipimpin oleh para insinyur asing kami yang terlatih, Menuju kepuasan pelanggan, personel kami yang berdedikasi akan berkomitmen untuk tugas mereka untuk mendukung pelanggan kami untuk mendapatkan nilai optimal dari produk dan layanan kami, dengan kepuasan pelanggan kami, kami mempertahankan partumbuhan kami dan menghormati kesetiaan yang terhormat dari orang-orang kami,

Penelitian ini tentang pengaruh Keselamatan dan Kesehatan Kerja (K3), Stres Kerja Terhadap Kinerja Karyawan PT. Ridar Essindo Tangerang. Hasil data dan informasi yang diperoleh akan dianalisis secara deskriptif pada pembahasannya. Kemudian akan dilakukan pengujian terhadap kerangka konseptual untuk mendapatkan model empiris

b) Hubungan Keselamatan dan Kesehatan Kerja Terhadap Kinerja

Hasil analisa model pengukuran menunjukkan bahwa keselamatan dan kesehatan kerja berpengaruh positif signifikan terhadap kinerja karyawan, Artinya, keselamatan dan kesehatan kerja merupakan faktor penting dalam pengimplementasian keputusan strategis manajemen sumber daya manusia. Sehingga perusahaan PT. Ridar Essindo bisa terus tumbuh dan berkelanjutan dalam persaingan pasar ke depannya. Oleh karena itu, kerangka konseptual yang dibangun pada model penelitian ini dapat diterima dan dibuktikan, karena memiliki hasil yang positif signifikan. Hasil penelitian ini didukung oleh penelitian (Prasetya, 2014) menyatakan bahwa keselamatan dan kesehatan kerja berpengaruh positif dan signifikan terhadap kinerja karyawan.

c) Hubungan Stres Kerja Terhadap Kinerja

Hasil analisa model pengukuran stres kerja berpengaruh positif, tetapi tidak signifikan terhadap kinerja, artinya stres kerja yang merupakan faktor penting untuk diperhatikan untuk mengitegrasikan atau menyelaraskan hubungan dari berbagai pemangku kepentingan

\section{KESIMPULAN DAN SARAN}

\section{A. SIMPULAN}

Berdasarkan hasil analisa kerangka konseptual yang dibangun tentang pengaruh Kesselamatan dan Kesehatan Kerja (K3), Stres Kerja Terhadap Kinerja Karyawan PT. Ridar Essindo. Sehingga, dapat disimpulkan sebagai berikut:

1. Keselamatan dan Kesehatan Kerja memiliki nilai t-hitung lebih besar dari t-tabel sebesar $4.358>1,677$ tingkat signifikansi 0.000 , dimana tingkat signifikansi 0.000 lebih kecil dari 0.05. Hal ini membuktikan bahwa keselamatan dan kesehatan kerja merupakan faktor penting dalam pengimplementasian keputusan strategis manajemen sumber daya manusia. Sehingga perusahaan PT. Ridar Essindo bisa terus tumbuh dan berkelanjutan dalam persaingan pasar ke depannya.

2. Stres kerja memiliki Nilai t-hitung lebih besar dari t-tabel sebesar $0,793>1,677$ dan nilai signifikasi lebih besar sebesar $0,464>0,05$. Hal ini menunjukan bahwa stres kerja berpengaruh terhadap kinerja karyawan tetapi tidak signifikan terhadap kinerja karyawan. Hal ini, menunjukkan bahwa stres kerja merupakan faktor penting untuk diperhatikan dalam mengitegrasikan atau menyelaraskan hubungan dari berbagai pemangku kepentingan PT. Ridar Essindo. Sehingga bisa diimplementasikannya keputusan strategis manajemen sumber daya manusia ke depannya dalam persaingan pasar yang dinamis.

3. Diketahui dari uji f, nilai probabilitas (sig) lebih kecil dari 0,05 atau 0,000 <0,05. Dan nilai $\mathrm{F}$ tabel $\leq \mathrm{F}$ hitung atau $3,20 \leq 27,396$. Nilai $F$ tabel 3,20 diperoleh dengan cara melihat $\mathrm{F}$ tabel dengan $\mathrm{df}=\mathrm{k}-1 \quad(3-1=2)$ dan $\mathrm{df}=\mathrm{n}-\mathrm{k} \quad(50-3=47)$ pada taraf signifikasi 0,05. Maka dapat disimpulkan 
bahwa Ho ditolak dan Ha diterima atau keselamatan dan kesehatan kerja $\left(\mathrm{X}_{1}\right)$ dan stres kerja $\left(\mathrm{X}_{2}\right)$ secara bersama-sama berpengaruh terhadap kinerja karyawan Keselamatan dan Kesehatan Kerja dan Stres Kerja memiliki pengaruh besar di PT. Ridar Essindo

\section{B. SARAN}

Ada beberapa aspek yang perlu direkomendasikan untuk menjadi bahan evaluasi dan pertimbangan, sehingga bisa diaplikasikan oleh PT. Ridar Essindo dan untuk penelitian selanjutnya, agar bisa menjadi solusi pengambilan keputusan startegis manajemen sumber daya manusia ke depannya, pihak-pihak yang direkomendasikan diantaranya: 1) Bagi PT Ridar Essindo, Untuk meningkatkan kinerja Karyawan PT. Ridar Essindo, maka keselamatan dan kesehatan kerja (K3) dan stres kerja merupakan faktor penting untuk dipertimbangkan dalam implementasi ke depannya, agar terciptanya kinerja karyawan untuk mencapai produktivitas unggul, 2) Bagi Bidang Akademik, Untuk penelitian selanjutnya, direkomendasikan untuk menganalisa kembali variabel-variabel yang digunakan dalam penelitian ini pada lokasi yang berbeda, dikarenakan ada beberapa variabel yang mampu mempengaruhi variabel dalam penelitian ini seperti komitmen dan dukungan, pelatihan dan konflik kerja.

\section{DAFTAR RUJUKAN}

Ashfaq, A. dan Muhammad, R. (2013). Effects of Job Stress on Employees Job Performance. Journal of Bussiness and Management (IOSR-JBM) Vol 11, issue 6.

Anjani, Mersya, Utami, Hamidah Nayati, Prasetya, Arik. (2014) "Pengaruh Keselamatan dan Kesehatan Kerja Terhadap Kinerja Karyawan" Jurnal Administrasi Bisnis (JAB), 9(1).

Ardana, I Komang, et al. (2015). Manajemen Sumber Daya Manusia.

Astianto Anggit, Suprihhadi Heru (2014) "Pengaruh Stres Kerja dan Beban Kerja Terhadap Kinerja" Jurnal Ilmu dan Riset Manajemen Vol.3 No.7 (2014)

Bangun, W. (2015). Manajemen Sumber Daya Manusia. Erlangga. Jakarta.
Edy Sutrisno. (2015). Manajemen Sumber Daya Manusia. Jakarta : Kencana Prenada Media Group.

Ghozali, Imam (2016). Aplikasi Analisis Multivariate dengan program SPSS. Edisi Ketujuh. Semarang : Badan Penerbit Unversitas Diponegoro.

Ghozali, imam (2014).Aplikasi IBM SPSS 19 (Edisi kelima) Semarang: Universitas Diponegoro.

Handoko, T.Hani. (2014). Manajemen Personalia dan Sumber Daya Manusia. Yogyakarta : Liberty

Hermita. (2014) Pengaruh Stres Kerja Terhadap Kinerja Karyawan Pada PT. Semen Tonasa (PERSERO) Pongkape. e Skripsi Fakultas Ekonomi Universitas Hasanudin Makasar.

Hasibuan, Malayu S.P. (2014). Manajemen Sumber Daya Manusia. Bumi Aksara, Jakarta.

Karabaya Erdilek Melisa, Akyuz Bulent, Elci Meral (2016) "Effects of Family-Work Conflict, Locus of Control, Self Confidence and Extraversion Personality on Employee Work Stress Melisa" Journal International Strategic Management Conference, ISMC (269-280).

Khan Ahmed Waqaf, Tabassum Anmol. (2014) "Occupational Health, Safety and Risk Analysis" Journal International of Science, Environment Vol 3, No 4 (1336-1346).

Leonora Elizabeth Steffany, Lapian (2016) "Analyzing The Effect Of Work Life Conflict and Job Stress On Employee Performance" Journal EMBA Vol 4 (1).

Mangkunegara (2016). Evaluasi Kinerja Sumber Daya Manusia. Bandung : PT. Rafika Naitama.

Mangkunegara, A. A. Anwar Prabu. (2014). Evaluasi Kinerja Sumber Daya Manusia. Bandung : Refika Aditama.

Murwansyah (2014). Manajemen Sumber Daya Manusia. Bandung : PT.Remaja Rosda Karya.

PT Ridar Essindo. (2018). Profil. http://www.ridaresindo.co.id/ 
Pratiwi, Agustin, Kuswinarto Mudji (2015) "Pengaruh Kompensasi Terhadap Kinerja Karyawan" Jurnal Pengaruh Kompensasi Terhadap Kinerja Karyawan.

Prayitno Hadi, Palupi Arum Ratna, Khairon (2015) "The Effect of Occupational Safety and Health on Work Productivity of Field Workers of Access Network Maintenance" Journal International of Sciences: Basic and Applied Research (IJSBAR) (2015) Vol 22, No 1, pp (257-262).

Riandy (2016) "Pengaruh Stres Kerja Terhadap Kinerja Karyawan" Jurnal Administrasi Bisnis 4 (4):1059-1072.

Rivai. (2014). Manajemen Sumber Daya Manusia Untuk Perusahaan : dari Teori Kepraktik, Jakarta : Raja Grafindo Persada.

Sedarmayanti (2014). Sumber Daya Manusia dan Produktivitas Kerja. Bandung : CV Mandar Maju.
Sugiyono, (2016). Metode Penelitian Bisnis.Bandung: Alfabeta.

Sunyoto, D. (2015). Manajemen Sumber Daya Manusia. Yogyakarta : CAPS.

Suwanto dan Priansa. (2014). Manajemen Sumber Daya Manusia Dalam Organisasi Publik Bisnis. Bandung (Alfabeta).

Triasmoko, Denny, Djudi Mukzam,Nurtjahjono Eko Gunawan. (2014) "Pengaruh Pelatihan Kerja Terhadap Kinerja Karyawan" Jurnal Administrasi Bisnis (JAB), 12(1).

Wibowo, (2016). Manajemen Kinerja. Edisi Ketiga. Jakarta: PT Raja Grafindo Persada.

Yani, H.M. (2015). Manajemen Sumber Daya Manusia, Edisi Asli, Penerbit Mitra Wacana Media: Jakarta. 